\title{
IS GENDER-BIASED LANGUAGE SEXIST? A PERCEPTUAL APPROACH
}

\author{
Nancy L. Murdock and Donelson R. Forsyth \\ Virginia Commonwealth University
}

Two studies were conducted to define reactions to gender-biased language empirically. In the first study, respondents evaluated the sexism in a series of sentences that contained no bias, used such words as man or he in the generic sense, or referred to women in an unfair, stereotypical manner. In the second study, reactions were examined in a more naturalistic context by asking respondents to evaluate an essay written using all plural pronouns, generic pronouns, or generic pronouns plus evaluative stereotypic phrasings. The results were consistent with the recommendations of the American Psychological Association's "Guidelines for Nonsexist Language" $(1975,1977)$ : (1) generic phrasings were perceived to be somewhat biased and sexist, (2) designation and evaluation stereotyping was perceived to be extremely biased and sexist, and (3) neutral alternatives were judged to be appropriately nonsexist. These findings suggest that authors should conform to the standards prescribed in the "Guidelines" if they hope to avoid unfair treatment of the sexes.

Because students are most familiar with the ways of the college professor, many choose academic careers which can range from the research scientist involved with man's search for knowledge to the psychologist trying to help solve his client's problems. Business is another attractive career area, with its high salaries and golden opportunities. The average corporate businessman probably earns at least twice the salary of the college prof, yet he probably has half the education. But business calls for ambitious men and aggressive women; the best man for the job is one who is not afraid to stand behind his opinions and ideas.

This article was the Award Presentation of the Southeastern Psychological Association Committee on the Equality of Professional Opportunity Research at the 1980 meetings of SEPA, Washington, DC.

Requests for reprints should be sent to either author at Virginia Commonwealth University, Richmond, VA 23284. 
In communicating with others, people sometimes use language styles and phrasings that can be viewed as gender-biased. For example, the preceding paragraph contains no fewer than eight such "errors," the most frequent being the use of forms of the pronoun he to refer to both males and females. This practice creates an ambiguity of referent problem: although no restriction may be warranted or intended, the reader might assume reference is being made only to males. Other generic phrasings, such as man for the job and businessman can similarly mislead readers, as can biased language forms that go beyond the problem of ambiguity to unfairly imply that women and men differ from one another in certain fundamental ways (American Psychological Association, 1975, 1977). For example, by referring to businesswomen as "aggressive" and businessmen as "ambitious," the paragraph implicitly reinforces stereotypes about men and women. Some gender-biased language forms, such as mothering or manhandling, even suggest that certain abilities or behaviors are gender specific.

Growing awareness of the problem of gender-biased language has led to a series of formal guidelines warning authors to exercise care in their word choices (American Psychological Association, 1975, 1977; John Wiley \& Sons, 1977; Harper \& Row Publishers, Inc., 1976; Holt, Rinehart, \& Winston, 1976). In addition, several studies also have examined the issue empirically, and have lent substantial support to the recommendations proffered in the guidelines. For example, Moulton, Robinson, and Elias (1978) report that college students who read sentences containing the word he used in the generic sense are far more likely to assume that men and not women are being described. MacKay (1980) reports similar findings, and adds that possible alternative pronouns $(E, e$, and tey) slow reading speed but are better understood to be gender neutral. However, although these and other authors (American Psychological Association, 1975; Bodine, 1975; Spencer, 1978) suggest that certain gender-biased styles are ambiguous, significant disagreement exists over the implications of these findings. For example, Lakoff (1973) agrees that the generic he does refer more to men than to women, but notes that the long-range consequences of the oft-used phrase may be fairly trivial. Others, in contrast, argue that the generic he creates and reinforces existing stereotypes concerning women and men (Geiwitz, 1978; Miller \& Swift, 1976). In other words, one perspective on the question "Is genderbiased language sexist?" suggests that terms like man and he, when used in the generic sense, are inaccurate but not sexist. The contrasting perspective argues that generic phrasings are not only inaccurate, but also sexist: they reinforce negative and discriminatory attitudes toward women. 
Although evidence concerning the degree to which gender-biased language is sexist language can be gathered in a variety of different ways (estimating the damaging economic, psychological, and social consequences of biased language, the impact of language on stereotypes about women and men, etc.), the current research focuses on individuals' judgments of gender-biased language. In the first study, college students read and evaluated the "degree of sexism" suggested by the phrasing and content of a series of sentences. Although several of the sentences were unbiased, most violated the American Psychological Association's "Guidelines for Nonsexist Language in APA Journals" (1977). A second study attempted to create a more naturalistic encounter with biased forms by embedding them in essays that subjects rated on a number of dimensions. Overall, we predicted that gender-biased language would be judged to be sexist, with stereotypic phrasings being more strongly condemned than generic usages. However, we also predicted that men, relative to women, would judge gender-biased language to be less sexist, and that these sex differences would in part be moderated by certain personality and attitudinal factors. Specifically, we hypothesized that gender-biased language would be evaluated as more sexist by people who manifested (a) an androgynous sex role orientation (Bem, 1974) or (b) a more positive attitude toward the role of women in contemporary society (Spence, Helmreich, \& Stapp, 1975).

\section{METHOD}

\section{Participants}

Subjects for both studies were volunteers recruited from evening classes at a large urban university. Although the sample was not a random one, the use of adult students in evening classes improved the representativeness of the group. Both studies included a large proportion of full-time students, but other occupations-secretaries, pharmacists, nurses, keypunch operators, homemakers, musicians, sales clerks, executives, and attorneys - were also represented. Study 1 involved 139 respondents with a mean age of 23 years, ranging from 17 to 47 . The sample included (where such information was provided) 40 men and 96 women, and 103 whites and 24 blacks. The 134 people who took part in Study 2 had a mean age of 24 years, ranging from 18 to 45 . This group included 87 women and 47 men, and 32 blacks and 96 whites. Subjects in both studies completed the experimental materials in the classroom. All signed informed consent forms, and no participant refused to participate in the research. 


\section{Personality Measures}

Prior to participation in either study all respondents completed the Attitudes Toward Women Scale (AWS) developed by Spence, Helmreich, and Stapp (1975). By median split, respondents were classified as either Traditional or Liberal in their attitudes toward the role of women in contemporary society. Respondents were also classified as Masculine, Feminine, Undifferentiated, or Androgynous on the basis of their responses to the Bem Sex Role Inventory (BSRI; Bem, 1974).

\section{Study 1}

Method. Respondents were asked to read and rate the sexism in each of the sentences shown in Table 1, assuming each statement was independent of all the others. Although some of the items used neutral phrasings, others were purposely biased by including generic pronouns and implied endorsements of sexist stereotypes. Perceptions of the sexism in each sentence were assessed using a 7-point Likert scale; verbal labels ranged from "not sexist at all" to "extremely sexist."

Results. The mean sexism ratings for all of the sentences are presented in Table 1, and a split plot ANOVA indicated the sentences were differentially evaluated; $F(29,3770)=88.59, p<.01$. When the items are reordered from those rated least sexist to those rated most sexist, they tend to cluster together to form the six different categories shown in Table 1: (1) nonsexist; (2) generic man in a commonplace word; (3) generic man and he; (4) ambiguous referent with evaluation; (5) designation stereotypes; and (6) evaluational stereotypes. Post hoc Duncan's Multiple Range tests indicated that perceptions of the sentences in these six clusters followed a clear-cut pattern, with items in the first cluster being more favorably evaluated than items in the second cluster, and so on.

Turning to possible individual differences, a $2 \times 4$ least squares MANOVA (sex by sex type) yielded no significant effects. In contrast, when ratings of sexism were analyzed in a $2 \times 2$ (sex by attitudes toward women) least squares MANOVA, a significant main effect of attitudes toward women was in evidence, $F(30,101)=2.25, p<.01$. As the rightmost columns of Table 1 show, on 19 of the 26 biased sentences, respondents with a Liberal attitude toward the role of women in contemporary society rated the sentences as more sexist than respondents who espoused more Traditional attitudes. However, Traditional respondents rated two of the nonbiased items as more sexist than did Liberal respondents. Lastly, although no a priori hypotheses concerning differences between respondents of varying 


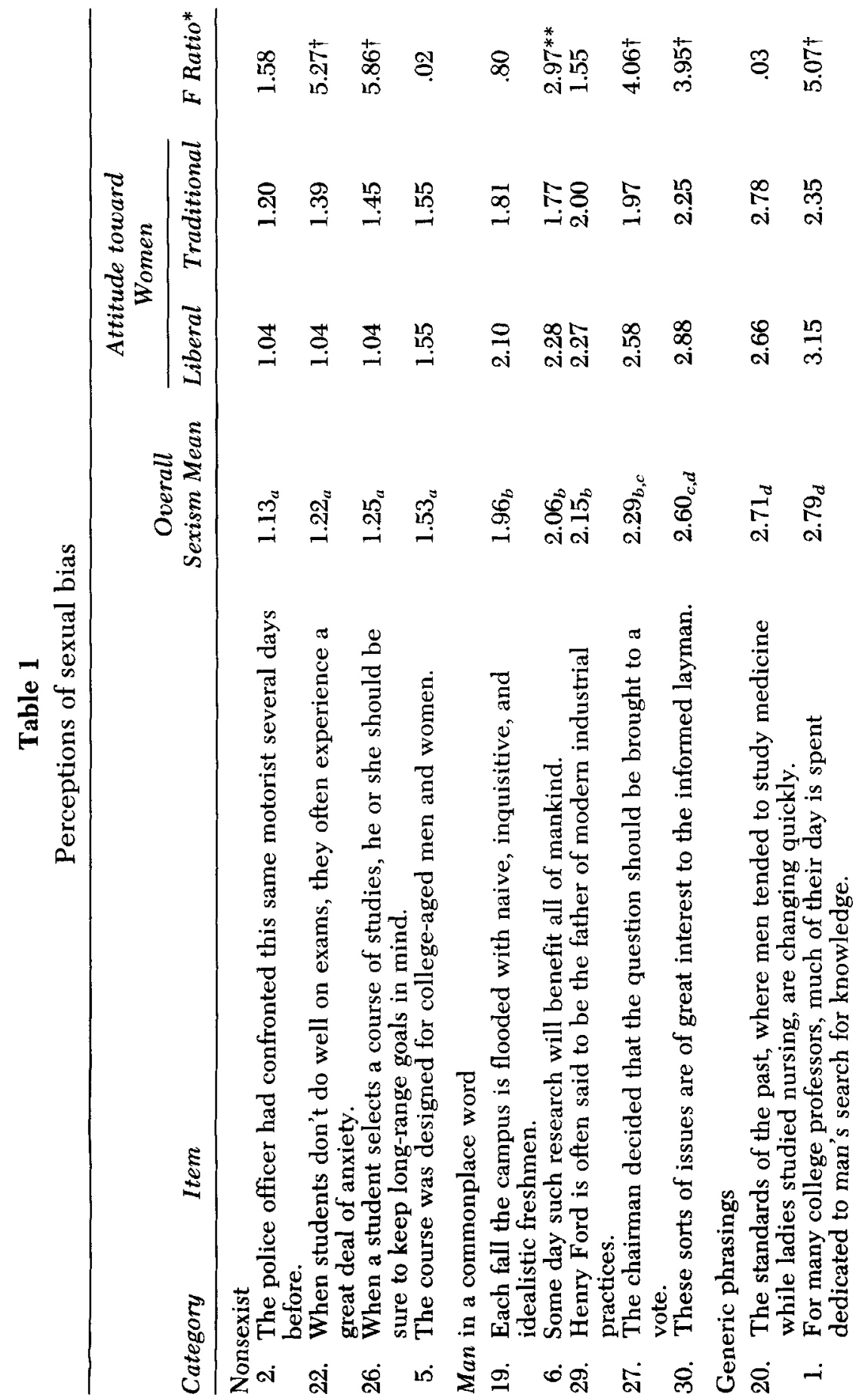




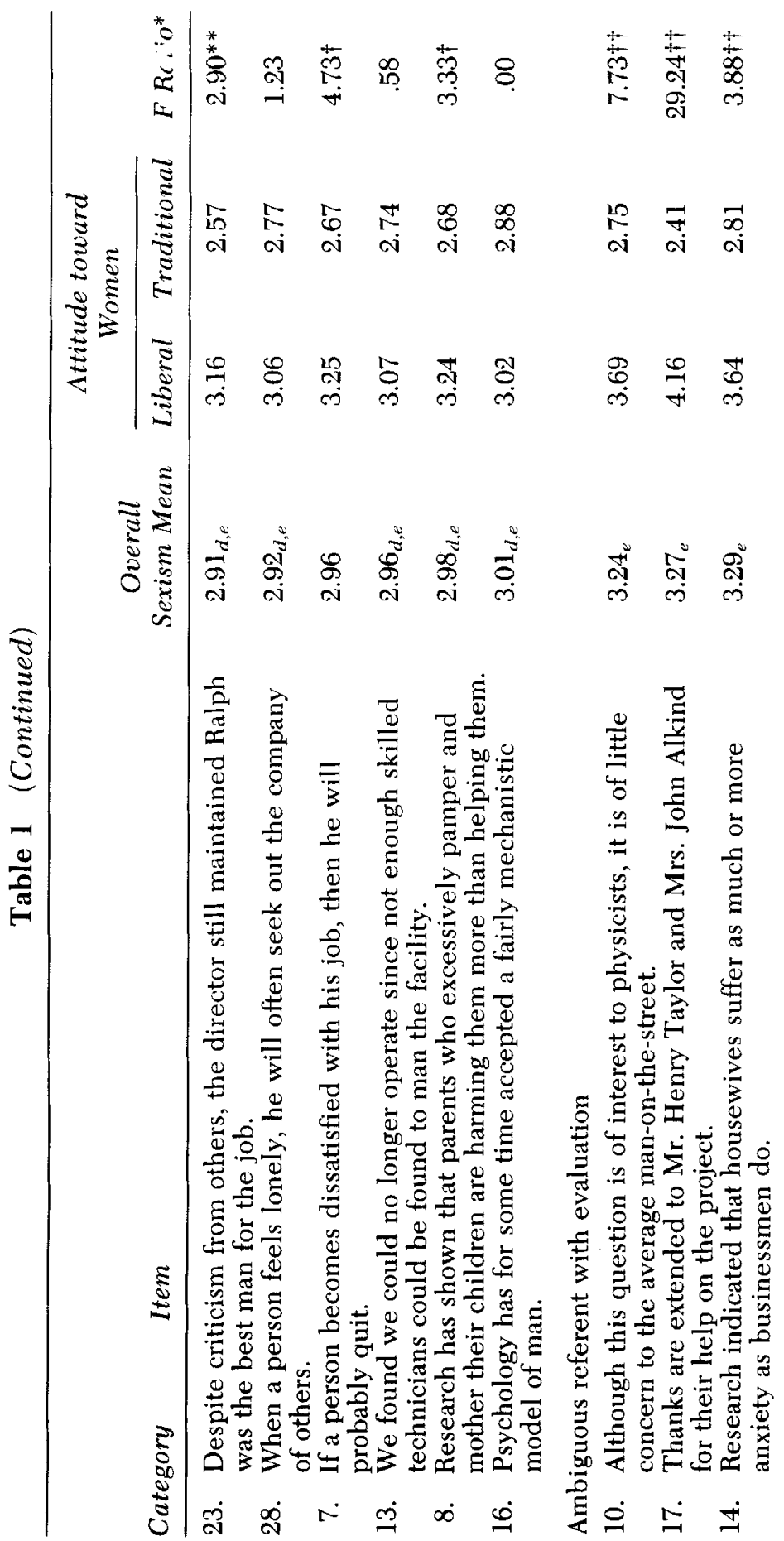




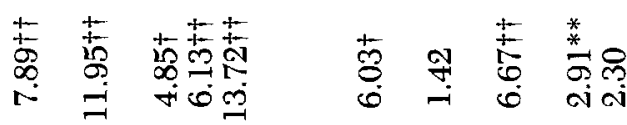

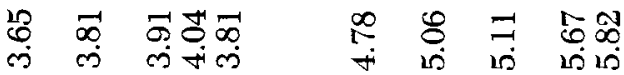

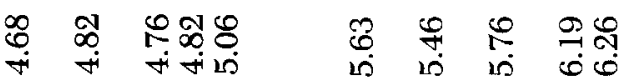

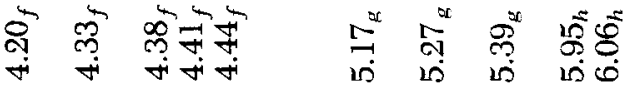

$\infty$

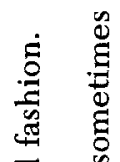

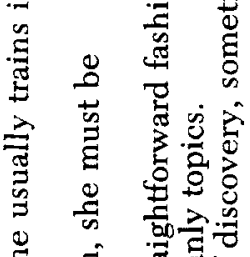

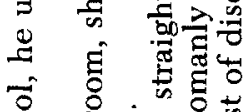

官

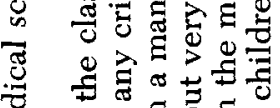

ฮే

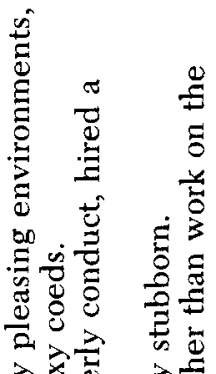

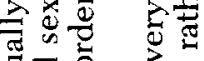

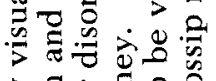

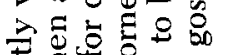

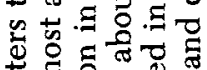

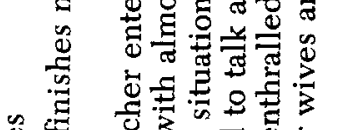

-

bo $\Phi$ 코월

5 50.

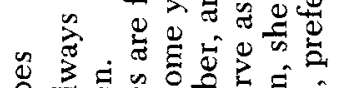

幽

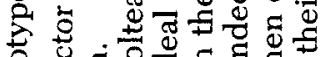

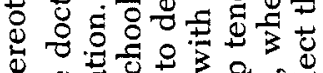

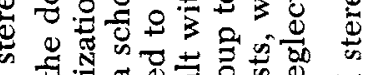

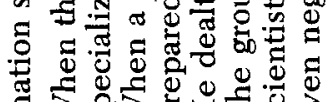

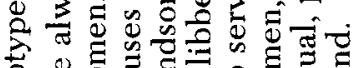

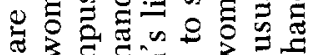

क

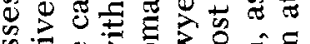
४ै ป के

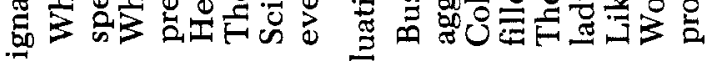
$\stackrel{0}{0}$ में 约 
races, marital status, age, and student status were advanced, exploratory analyses revealed no effects of these demographic and individual-difference variables.

\section{Study 2}

Method. Participants read and rated for perceived sexism one of three essays, attributed to another student, but in actuality prepared so as to vary in level of gender bias. A paragraph from the biased essay was presented in the introduction to this article; it contained both generic pronouns and stereotypic, evaluative language. The generic essay, in contrast, used only generic language forms, whereas the neutral essay conformed to the American Psychological Association (APA) "Guidelines" (1975, 1977) for gender-neutral language. After reading the essay, subjects completed an 8-item questionnaire containing filler items assessing memory for content, reaction to writing style, and interest level. Four items embedded in this questionnaire, however, measured perceptions of sexism in the essay.

Results. As in Study 1, the ratings were analyzed by race, marital status, age, student status, and BSRI score (to check for confounding sources of variance), but again no effects were found. Therefore, the results reported below are based on a 2 (sex) $\times 2$ (attitude toward women) $\times 3$ (language in essay: biased, generic, neutral) least squares analysis of variance of the four 9-point rating scales.

Strong main effects of language of essay were in evidence on the items "Did the author's writing style unfairly emphasize one sex more than another?" and "How sexist was the author's writing style?"; $F(2$, 122 ) $=9.32$ and 10.22 , respectively, $p<.05$ for both (the endpoints for the two items were, respectively, favored females much more versus favored males much more and very sexist versus not at all sexist). The essay that used all plural pronouns and neutral language structures was rated as favoring neither $\operatorname{sex}(M=4.9)$ and not at all sexist $(M=1.4)$. The generic essay, in contrast, was judged to be slightly biased in the male direction $(M=4.7)$ and more sexist $(M=2.5)$. Last, the essay that used both generic language and stereotyping was rated as the most biased in a masculine direction $(M=4.1)$ and the most sexist $(M=3.1)$.

Effects also were revealed on two ancillary items. First, an interaction of attitude toward women and language on the item "Do you think the author was a male or a female?", $F(2,121)=4.79, p<.05$, indicated that although Traditional respondents were uncertain about the gender of the person who wrote the biased essay $(M=4.2)$, Liberal respondents believed the author was probably male $(M=3.2)$. The 
remaining means did not differ from one another (Libern!/generic essay $M=39 ;$ Liberal/neutral essay $M=4.9$; Tradition $1 /$ generic essay $M=4.2$; and Traditional/neutral essay $M=4.4$ ). Second, main effects of sex and attitude toward women were obtained on the item "In all honesty, do you think the issue of sexist language usage is important or trivial?"; $F(1,22)=6.95$ and 18.42 , respectively, $p<.05$ for both. Males and Traditionals felt the issue was trivial $(\boldsymbol{M}=3.7$ and 3.8, respectively), whereas females and more Liberal respondents rated the issue as somewhat more important $(M=5.1$ and 5.6 , respectively).

\section{DISCUSSION}

The results of the two studies, taken in combination, indicate that certain gender-biased language forms are perceived to be sexist. Indeed, a remarkably consistent pattern of evaluations was obtained that closely parallels the categories identified in the "Guidelines for Nonsexist Language" (APA, 1977). When the content of the written materials was varied from low gender bias to high gender bias, subjects' evaluations ranged from low perceived sexism to very high perceived sexism. Thus, the findings suggest that judgments of sexism will increase along a continuum as language ranges from neutrality, to the use of he and man in a generic sense, to ambiguous referents with implicit evaluations of women and men, and to designation and evaluative stereotypes.

The present research, however, demonstrated that all do not agree concerning the sexist nature of masculine-biased language. On many of the items, respondents with differing attitudes toward the role of women in contemporary society were in dispute: those with liberal attitudes felt that biased forms were more sexist than their more conservative counterparts. Also, Liberal respondents were more certain that the writer of a sexist essay was male, and also considered the issue of sexual bias to be of greater importance than Traditional respondents. Furthermore, males more than females suggested that the issue of sexually biased language was trivial. This finding suggests that the debate over the use of nonbiased forms may be complicated by some males' unstated assumption that no alternatives to the presently used forms are necessary. Nevertheless, both studies did indicate that the alternatives for eliminating sexual bias from language were generally well received.

Although at one level these results provide confirmation for the "Guidelines" promulgated by APA, for empirical and philosophical reasons one could argue that these findings are only obliquely related to the basic issues. On the empirical side, although steps were taken 
to assess the reactions of a cross-section of those who may be exposed to sexist language, the "convenience" sampling techniques used in the present research were not sufficient to ensure a representative picture of individuals' perceptions of sexist language. In addition, the directness of the studies-with explicit questions concerning sexism in language and presentation of multiple examples of sexist sentences-could have biased subjects' responses. Furthermore, on the philosophical side, to argue that policy judgments should be congruent with public opinion is to commit the "naturalistic fallacy" of reasoning that "what is ought to be." Simply because people do, in fact, reject gender-biased phrasings does not necessarily mean that such phrasings are "wrong." However, although the relationship between data and policy is always a tenuous one, even a conservative interpretation of the current findings suggests that many people feel that genderbiased language is sexist.

On the positive side, these findings are important for they better establish a link that was only implicitly assumed in previous discussions and research: that gender-biased language is sexist-at least in the eyes of some people. Furthermore, the judgments of the group that can, in a sense, be considered the ultimate judges on the issuewomen with forwardlooking attitudes about their role in societymatched the recommendations of the panel of experts responsible for the American Psychological Association's guidelines. Given these considerations, this research recommends that authors who hope to use language that will be viewed as nonsexist closely adhere to the "Guidelines."

\section{REFERENCES}

American Psychological Association. (1975). Guidelines for nonsexist language. American Psychologist, 30, 682-684.

American Psychological Association. (1977). Guidelines for nonsexist language in APA journals. American Psychologist, 32, 487-494.

Bem, S.L. (1974). The measurement of psychological androgyny. Journal of Consulting and Clinical Psychology, 42, 155-162.

Bodine, A. (1975). Androcentrism in prescriptive grammar: Singular "they," sex-indefinite "he" and "he or she." Language in Society, 4, 129-146.

Geiwitz, J. (1978, August). Another plea for E. APA Monitor, p. 3.

Harper \& Row Publishers, Inc. (1976). Harper and Row guidelines on equal treatment of the sexes in textbooks. New York: Author.

Holt, Rinehart \& Winston (College Division). (1976). The treatment of sex roles and minorities. New York: Author.

John Wiley \& Sons, Inc. (1977). Wiley guidelines on sexism in language. New York: Author.

Lakoff, R. (1973). Language and woman's place. Language in Society, 2, 45-80.

Mackay, D.G. (1980). Psychology, prescriptive grammar, and the pronoun problem. American Psychologist, 35, 444-449. 
Miller, C., \& Swift, K. (1976). Words and women: New language in new times. Garden City, NJ: Doubleday.

Moulton, J., Robinson, G., \& Elias, C. (1978). Sex bias in language use. American Psychologist, 33, 1032-1036.

Spence, J.T., Helmreich, R., \& Stapp, J. (1975). Ratings of self and peers on sex role attributes and their relation to self-esteem and conceptions of masculinity and femininity. Journal of Personality and Social Psychology, 32, 29-39.

Spencer, N.J. (1978). Can "she" and "he" coexist? American Psychologist, 33, 782-783. 